\title{
Rancang Bangun Sistem Pengaman Sepeda Motor Menggunakan Radio Frequency Identification (RFID) dan Notifikasi Melalui Handphone
}

\author{
Meli Mildawati*, Wildian \\ Jurusan Fisika FMIPA Universitas Andalas, Padang \\ Kampus Unand Limau Manis, Pauh Padang 25163 \\ *melimm942@gmail.com
}

\begin{abstract}
ABSTRAK
Sistem pengaman sepeda motor menggunakan radio frequency identification (RFID) dan notifikasi melalui handphone yang dikontrol dengan modul Arduino Uno telah dirancang bangun. RFID terdiri dari sebuah RFID tag dan RFID reader. RFID tag yang memiliki kode yang berbeda-beda, digunakan sebagai kunci untuk menghidupkan sepeda motor setelah kunci kontak digunakan. RFID reader dapat membaca tag pada jarak maksimal $1,26 \mathrm{~cm}$. Sepeda motor yang dihidupkan tanpa menggunakan RFID tag atau RFID tag tidak sesuai menyebabkan aktifnya reed switch pada pelek roda depan. Ketika roda telah berputar sebanyak empat kali, maka alarm aktif dan GSM SIM 800L mengirimkan notifikasi berupa SMS sebanyak satu kali dan misscall sebanyak tiga kali ke nomor handphone pemilik sepeda motor. Waktu delay rata-rata SMS dan miscall berturut-turut adalah 5,42 s, 8,62 s, 61,14 s dan 113,16 s.

Kata kunci: sistem pengaman sepeda motor, RFID, Arduino Uno, reed switch, GSM SIM 800L,
\end{abstract}

\section{ABSTRACT}

Motorcycle safety systems using radio frequency identification (RFID) and mobile notifications controlled by the Arduino Uno module have been designed. RFID consists of an RFID tag and RFID reader. RFID tags that have different codes are used as keys to turn on a motorcycle after the ignition is used. The RFID reader can read tags at a maximum distance of $1.26 \mathrm{~cm}$. Motorbikes that are turned on without using RFID tags or RFID tags are not suitable causing active reed switches on the front wheel rim. When the wheel has rotated four times, then the alarm is active and GSM SIM 800L sends a notification in the form of an SMS once and misscall three times to the cellphone number of the motorcycle owner. The average SMS and miscall delay times are $5.42 \mathrm{~s}, 8.62 \mathrm{~s}, 61.14 \mathrm{~s}$ and $113.16 \mathrm{~s}$. Keywords: motorcycle safety system, RFID, Arduino Uno, reed switch, GSM SIM 800L

\section{PENDAHULUAN}

Jumlah penggunaan sepeda motor sebagai sarana transportasi di Indonesia selalu mengalami peningkatan sekitar 5\% setiap tahunnya (Badan Pusat Statistik, 2017). Kasus pencurian sepeda motor semakin sering terjadi yang menyebabkan para pemilik sepeda motor khawatir terhadap keamanan sepeda motornya.

Sistem pengaman tambahan pada sepeda motor telah dibuat dengan menggunakan mikrokontroler dengan Short Message Service (SMS) dan alarm sebagai peringatan (Rachmat dan Julian, 2016). Saklar diletakkan pada tempat yang tersembunyi yaitu di dalam bagasi motor. Ketika saklar diaktifkan dan kunci kontak dinyalakan, maka klakson akan langsung berbunyi dan mesin sepeda motor tidak dapat dihidupkan. Handphone pemilik akan menerima SMS "motor anda dicuri" dalam waktu 3-5 detik yang disertai panggilan telepon sebanyak 3 kali.

Sistem pengaman lainnya telah dibuat dengan menggabungkan sistem RFID dengan sensor reed switch dan alarm sebagai notifikasinya (Hakim, 2017). Sandi unik yang terkandung dalam RFID tag digunakan sebagai kunci untuk mengidentifikasi pemilik sepeda motor, dan sandi tersebut akan dibaca oleh RFID reader yang dipasang pada sepeda motor. RFID reader ini dapat membaca tag pada jarak maksimal $3,5 \mathrm{~cm}$. Saat motor dalam keadaan OFF, sensor reed switch yang dipasang pada roda akan mendeteksi pergerakan sepeda motor dengan cara mencacah jumlah putaran roda dan mengaktifkan alarm ketika cacahan mencapai jumlah tertentu. Sistem pengaman sepeda motor ini dikendalikan oleh mikrokontroler ATmega328 pada modul Arduino Uno R3. Sistem ini kurang efisien ketika pemilik dengan sepeda motor berjauhan, sehingga notifikasi yang diberikan alarm kepada pemilik sepeda motor tidak dapat berfungsi dengan baik. 


\section{METODE}

Metode yang digunakan dalam penelitian ini adalah metode rancang bangun, meliputi perancangan diagram alir sistem, perancangan dan pengujian sensor reed switch, perancangan dan pengujian RFID, perancangan dan pengujian GSM SIM800L, pengujian delay SMS dan misscall, perancangan rangkaian keseluruhan dan perancangan bentuk fisik dan pengujian alat.

\subsection{Perancangan Diagram Alir Sistem}

Diagram alir sistem merupakan diagram yang menjelaskan proses kerja suatu sistem. Mulai dari proses menghidupkan atau mematikan kendaran hingga mengaktifkan dan mematikan alarm keamanan. Diagram alir sistem dapat dilihat pada Gambar 1.
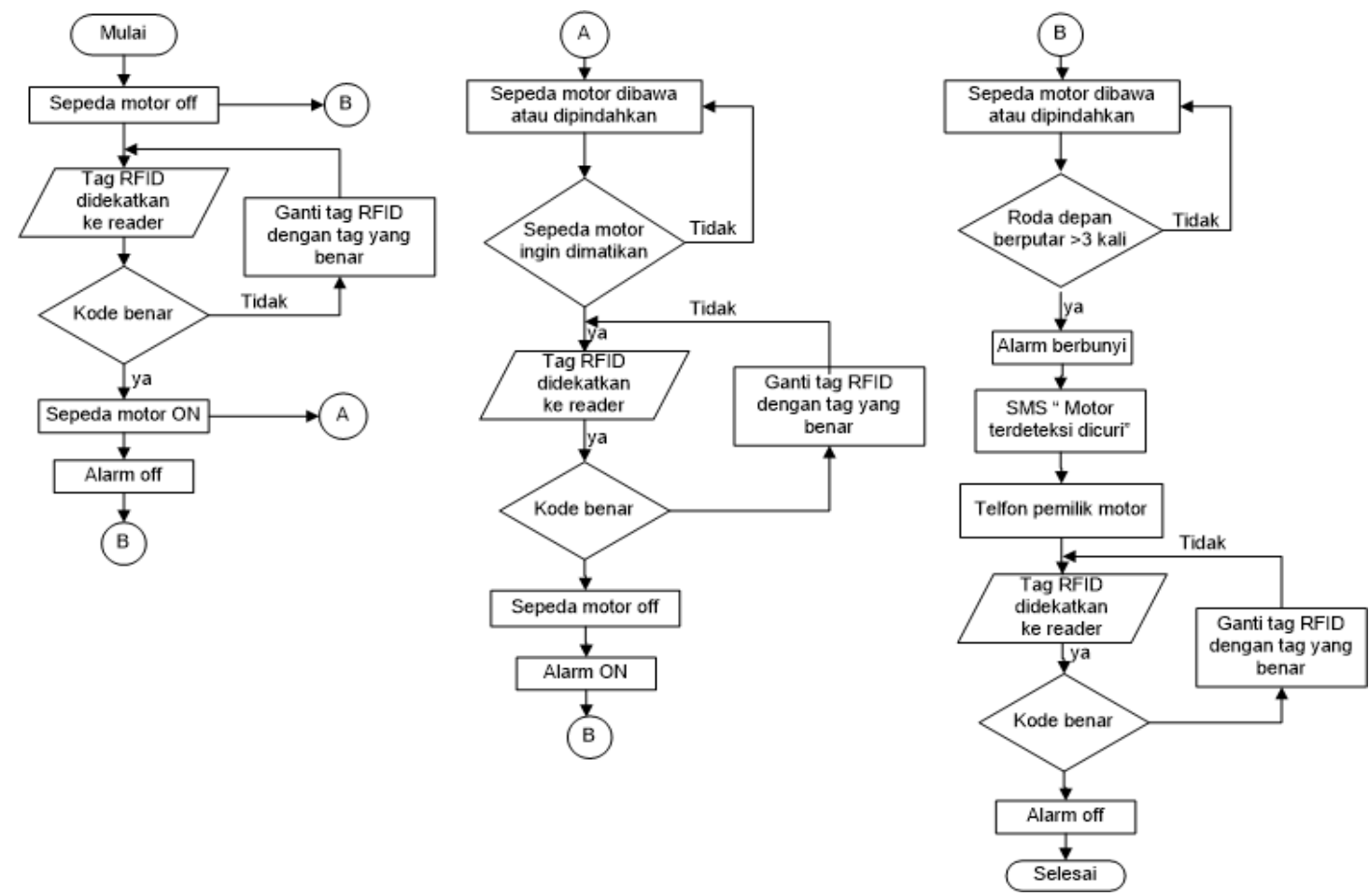

Gambar 1 Diagram alir sistem keseluruhan

\subsection{Karakterisasi Sensor Reed Switch}

Karakterisasi sensor reed switch dilakukan dengan memasangkan sensor dengan catu daya dan LED sebagai indikator. Kemudian magnet dilewatkan atau didekatkan disekitar sensor. Kemudian jarak deteksi maksimum magnet permanen oleh sensor reed switch ditentukan. Gambar 2 merupakan rangkaian untuk mengkarakterisasi sensor reed switch yang digunakan.

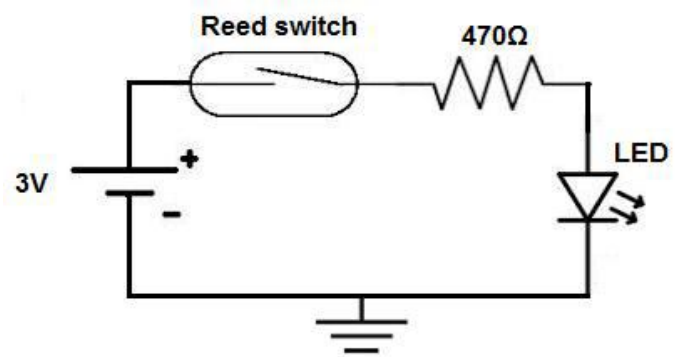

Gambar 2 Rangkaian karakterisasi sensor reed switch (Sumber : Veigas dkk., 2016) 


\subsection{Karakterisasi RFID}

Karakterisasi RFID dilakukan untuk melihat kode-kode unik yang dimiliki oleh RFID tag. Karakterisasi ini juga dilakukan untuk menentukan jarak baca maksimum RFID reader terhadap RFID tag. RFID yang digunakan adalah RFID RC255. Reader dihubungkan dengan Arduino menggunakan jumper seperti pada Gambar 3. Tag didekatkan ke reader dan diukur jarak maksimum antara tag dan reader saat kode-kode unik terbaca oleh reader. Tag yang digunakan dapat berupa kartu atau gantungan kunci sesuai bentuk tag yang disediakan.

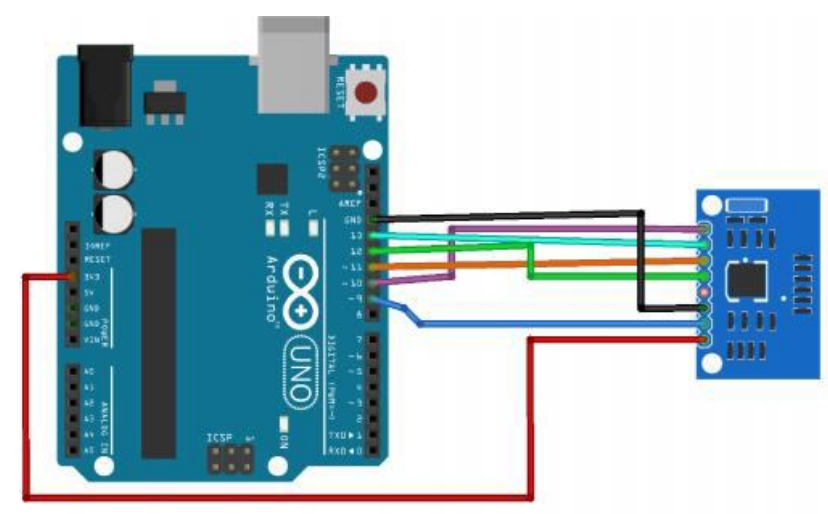

Gambar 3 Rangkaian uji sensor RFID (Sumber : Mukherjee, 2016)

\subsection{Perancangan Sistem Relay}

Perancangan sistem relay dilakukan berdasarkan Gambar 4. Masing-masing komponen disolder pada papan PCB. Perancangan ini bertujuan sebagai saklar yang digunakan untuk menghidupkan dan mematikan sistem kelistrikan pada kunci kontak. Dengan kata lain, relay tersebut yang digunakan sebagai pengganti kunci kontak sepeda motor.

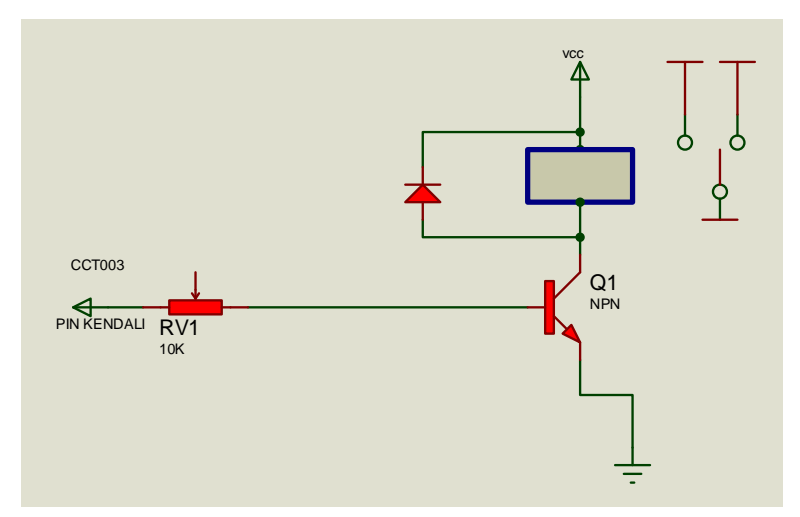

Gambar 4 Rancangan sistem relay

\subsection{Pengujian Modul SIM800L}

Pengujian pengiriman SMS dan misscall dilakukan ketika sensor reed switch telah mendeteksi keberadaan magnet permanen sebanyak empat kali. Pengujian SIM 800L untuk SMS dilakukan setelah proses uploading pada program, kemudian SIM 800L langsung melakukan panggilan (misscall) ke nomor yang telah didaftarkan pada program.

Hasil dari pengujian jumlah penerima SMS digunakan untuk menentukan layak atau tidaknya SIM800L dijadikan sebagai transceiver pada penelitian ini. 


\subsection{Pengujian Delay SMS dan Misscall}

Pengujian ini dilakukan untuk mengetahui waktu yang dibutuhkan sistem pengaman ini untuk mengirimkan SMS sampai ke handphone pemilik yakni nomor (+628527206XXXX). Perhitungan waktu dimulai dari pada saat sensor reed switch telah mendeteksi keberadaan magnet permanen sebanyak empat kali sampai SMS dan misscall masuk ke handphone pemilik. Hasil catatan waktu yang diperoleh dengan menggunakan stopwatch.

\subsection{Perancangan Rangkaian Keseluruhan}

Pada pengujian sistem secara keseluruhan masing-masing komponen dipasang pada Arduino menggunakan jumper seperti pada Gambar 5. Pengujian dilakukan untuk melihat apakah komponen-komponen tersebut dapat terkomposisi dengan baik dan bekerja sesuai dengan perintah pada program yang telah dibuat.

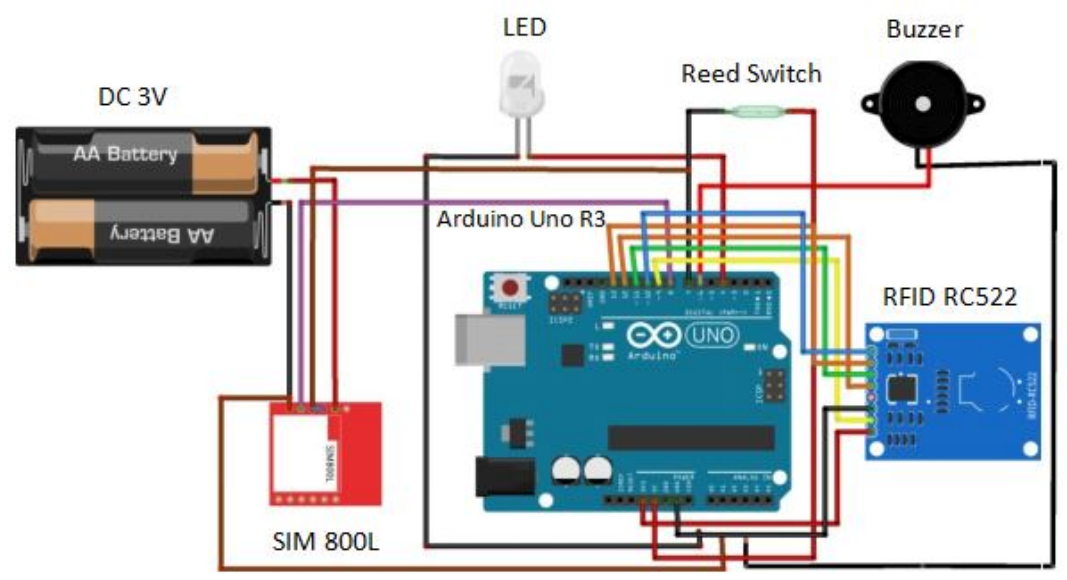

Gambar 5 Rangkaian alat secara keseluruhan

\subsection{Perancangan Bentuk Fisik dan Pengujian Alat}

Pemasangan alat dilakukan sedemikian rupa pada kendaraan bermotor tanpa mengubah bentuk kendaran. Pemasangan ini ditunjukkan pada Gambar 6. Arduino Uno, RFID reader, relay, SIM 800L dan buzzer diletakkan dalam sebuah kotak yang diletakkan dalam bagasi motor. Sensor reed switch dihubungkan ke Arduino yang ada di dalam kotak menggunakan kabel pelangi atau sejenisnya. Sensor reed switch dan magnet dipasang pada pelek roda depan. Hubungan masing-masing komponen dipasang seperti pada pengujian sistem secara keseluruhan.

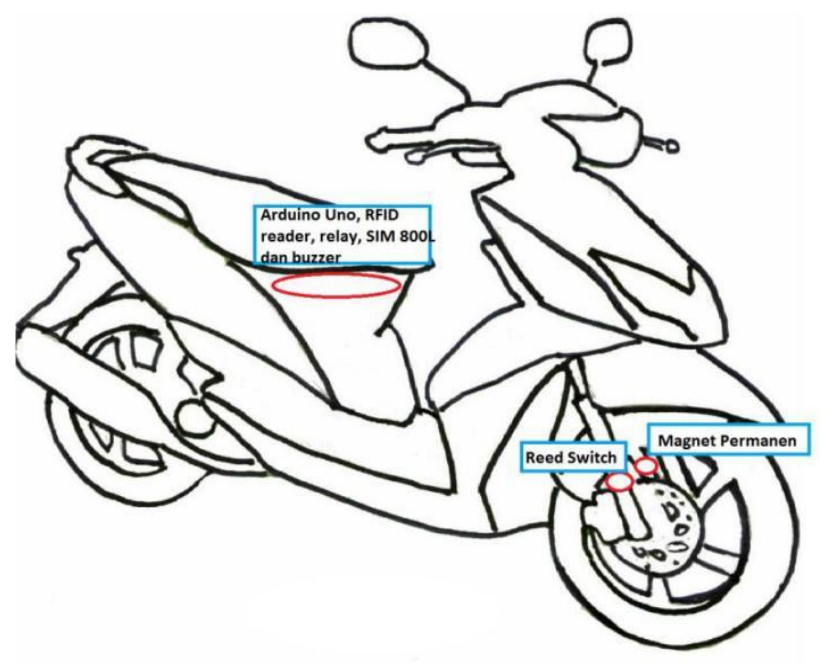

Gambar 6 Pemasangan prototipe pada sepeda motor 


\section{HASIL DAN DISKUSI}

\subsection{Hasil Karakterisasi Sensor Reed Switch}

Karakterisasi sensor reed switch dilakukan dengan mengukur jarak deteksi sensor. Pengukuran ini dilakukan dengan dua cara, yaitu dengan mendekatkan dan menjauhkan magnet permanen pada sensor. Hasil pengukuran tersebut dapat dilihat pada Tabel 1 dan Tabel 2.

Tabel 1 Pengukuran Daerah Kerja Sensor Saat Magnet menjauhi Sensor

\begin{tabular}{cccccc}
\hline \multicolumn{2}{c}{ Percobaan Pertama } & \multicolumn{2}{c}{ Percobaan Kedua } & \multicolumn{2}{c}{ Percobaan Ketiga } \\
\hline $\begin{array}{c}\text { Jarak } \\
(\mathbf{c m})\end{array}$ & $\begin{array}{c}\text { Kondisi } \\
\text { sensor }\end{array}$ & Jarak $(\mathbf{c m})$ & $\begin{array}{c}\text { Kondisi } \\
\text { sensor }\end{array}$ & Jarak $(\mathbf{c m})$ & $\begin{array}{c}\text { Kondisi } \\
\text { sensor }\end{array}$ \\
\hline 3,1 & Terbuka & 3,1 & Terbuka & 3,1 & Tertutup \\
3,2 & Terbuka & 3,2 & Terbuka & 3,2 & Terbuka \\
3,3 & Terbuka & 3,3 & Terbuka & 3,3 & Terbuka \\
3,4 & Terbuka & 3,4 & Terbuka & 3,4 & Terbuka \\
3,5 & Terbuka & 3,5 & Terbuka & 3,5 & Terbuka \\
\hline
\end{tabular}

Tabel 2 Pengukuran Daerah Kerja Sensor Saat Magnet mendekati Sensor

\begin{tabular}{cccccc}
\hline \multicolumn{2}{c}{ Percobaan Pertama } & \multicolumn{2}{c}{ Percobaan Kedua } & \multicolumn{2}{c}{ Percobaan Ketiga } \\
\hline Jarak (cm) & Kondisi sensor & Jarak (cm) & $\begin{array}{c}\text { Kondisi } \\
\text { sensor }\end{array}$ & $\begin{array}{c}\text { Jarak } \\
(\mathbf{c m})\end{array}$ & $\begin{array}{c}\text { Kondisi } \\
\text { sensor }\end{array}$ \\
\hline 2,5 & Terbuka & 2,5 & Terbuka & 2,5 & Terbuka \\
2,4 & Terbuka & 2,4 & Terbuka & 2,4 & Terbuka \\
2,3 & Tertutup & 2,3 & Tertutup & 2,3 & Tertutup \\
2,2 & Tertutup & 2,2 & Tertutup & 2,2 & Tertutup \\
2,1 & Tertutup & 2,1 & Tertutup & 2,1 & Tertutup \\
\hline
\end{tabular}

Jarak maksimum rata-rata yang didapatkan dari tiga kali percobaan saat pengukuran daerah kerja sensor saat magnet menjauhi dan mendekati sensor yaitu $3,13 \mathrm{~cm}$ dan $2,3 \mathrm{~cm}$. Pemasangan sensor reed switch harus diatur sedemikian rupa agar magnet dapat melewati daerah aktif sensor.

\subsection{Hasil Karakterisasi RFID MFRC522}

Karakterisasi dilakukan dengan merangkai RFID MFRC 522 bersama Arduino menggunakan program DumpInfo yang telah tersedia pada library IDE Arduino. Pengukuran jarak baca reader terhadap tag dilakukan untuk menentukan jarak maksimum reader mampu membaca kode yang dimiliki tag. Pengukuran jarak baca dilakukan dengan menggunakan penggaris. Hasil pengukuran dapat dilihat pada Tabel 3.

Tabel 3 Pengukuran jarak baca reader terhadap tag (stiker)

\begin{tabular}{cccccc}
\hline \multicolumn{2}{c}{ Percobaan Pertama } & \multicolumn{2}{c}{ Percobaan Kedua } & \multicolumn{2}{c}{ Percobaan Ketiga } \\
\hline Jarak $(\mathbf{c m})$ & Keterangan & Jarak $(\mathbf{c m})$ & Keterangan & Jarak $(\mathbf{c m})$ & Keterangan \\
\hline 1,1 & Terbaca & 1,1 & Terbaca & 1,1 & Terbaca \\
1,2 & Terbaca & 1,2 & Terbaca & 1,2 & Terbaca \\
1,3 & Terbaca & 1,3 & Terbaca & 1,3 & Tidak terbaca \\
1,4 & Tidak terbaca & 1,4 & Tidak terbaca & 1,4 & Tidak terbaca \\
1,5 & Tidak terbaca & 1,5 & Tidak terbaca & 1,5 & Tidak terbaca \\
\hline
\end{tabular}

Jarak maksimum pembacaan oleh reader adalah 1,26 cm (tag berbentuk stiker) pada posisi sejajar antara tag dan reader. Pembacaan kode tidak dapat terjadi jika posisi keduanya saling tegak lurus. Hasil ini sesuai dengan teori yang telah dijelaskan pada bab sebelumnya dimana tag hanya dapat menerima induksi magnetik jika posisinya sejajar dengan reader.

\subsection{Pengujian Sistem Relay}

Pengujian sistem relay dilakukan untuk memastikan relay dapat bekerja dengan baik dan dapat digunakan sebagai saklar yang menggantikan kerja kunci kontak sepeda motor. Relay yang digunakan adalah relay $5 \mathrm{~V}$ karena dapat bekerja pada tegangan $5 \mathrm{~V}$ sehingga dapat 
menggunakan tegangan dari Arduino. Saat diberi input, relay dapat bekerja dengan baik (menghidupkan dan mematikan sistem kelistrikan pada kunci kontak). relay dihubungkan dengan kontak sepeda motor dan sistem RFID, apabila kode RFID tag yang digunakan sesuai dengan kode yang telah diinputkan dalam program maka kedua reed pada relay terhubung dan kontak dapat ON. Apabila kode pada RFID tag tidak sesuai dengan kode yang telah diinputkan pada program atau sepeda motor dihidupkan tanpa menggunakan RFID tag maka sepeda motor tidak dapat menyala karena kedua reed pada relay tidak terhubung atau kontak tetap dalam keadaan OFF.

\subsection{Hasil Perancangan dan Pengujian SIM 800L}

Perancangan dan pengujian SIM 800L dilakukan untuk memastikan SIM 800L yang digunakan sudah dapat berfungsi dengan baik atau tidak. Pengujian dilakukan dengan mengupload program send SMS untuk SMS pada dan program GPRS call_up untuk misscall yang dikirimkan dari nomor SIM dalam SIM800L ke tiga nomor SIM berbeda pada Tabel 4.

Tabel 4 Pengujian pengiriman SMS dan misscall

\begin{tabular}{cccc}
\hline Nomor Handphone & Indikator Keberhasilan & Jarak & Keterangan \\
\hline 085272066289 & $\begin{array}{c}\text { SMS dan misscall } \\
\text { berhasil diterima }\end{array}$ & $10 \mathrm{~cm}$ & $\begin{array}{c}\text { Di tempat yang sama dengan } \\
\text { tempat penerimaan SMS }\end{array}$ \\
\hline 085265491148 & $\begin{array}{c}\text { SMS dan misscall } \\
\text { berhasil diterima }\end{array}$ & $74,4 \mathrm{~km}$ & $\begin{array}{c}\text { Kudu, kec V Koto Timur, } \\
\text { Padang Pariaman }\end{array}$ \\
\hline 085265007190 & $\begin{array}{c}\text { SMS dan misscall } \\
\text { berhasil diterima }\end{array}$ & $2.157 \mathrm{~km}$ & $\begin{array}{c}\text { Apartemen Gunawangsa } \\
\text { Manyar, Jl. Menur Pumpungan } \\
\text { no. 62, Kec. Sukolilo, } \\
\text { Surabaya }\end{array}$ \\
\hline
\end{tabular}

\subsection{Pemasangan Alat}

Alat yang telah diuji sebelumnya, dipasang pada sepeda motor pada tempat-tempat yang telah ditentukan. Pemasangan alat ditempatkan sedemikian rupa agar tidak merubah bentuk atau fungsi dari bagian sepeda motor. Pada penelitian ini pemasangan alat dilakukan pada sepeda motor merek HONDA BeAT-FI CBS Techno White. Masing-masing komponen dihubungkan menggunakan kabel pelangi atau semacamnya dengan panjang yang dapat disesuaikan dengan kebutuhan..

Sensor reed switch dipasang pada pelek roda depan dan magnet permanen ditempelkan di lingkaran besi roda depan yang sejajar dengan pelek roda tempat sensor reed switch dipasang. Sensor reed switch nantinya mendeteksi keberadaan magnet permanen yang apabila telah terdeteksi lebih dari tiga kali maka notifikasi berupa buzzer berbunyi dan SMS serta misscall kepada nomor hanphone pemilik sepeda motor dikirimkan. Arduino Uno, RFID reader, relay, SIM 800L dan buzzer digabungkan pada sebuah kotak yang diletakkan dalam bagasi sepeda motor.

\subsection{Pengujian Sistem Pengaman Secara Keseluruhan}

Uji coba keseluruhan dimulai dari ketika RFID reader membaca kode salah dari RFID tag yang digunakan atau sepeda motor diaktifkan tanpa RFID tag maka sepeda motor tidak dapat menyala. Sistem pengaman kedua kemudian aktif, yaitu ketika sensor reed switch telah membaca perputaran roda sebanyak empat kali maka buzzer berbunyi dan SIM 800L mengirimkan notifikasi berupa SMS sebanyak satu kali disertai dengan panggilan misscall sebanyak tiga kali ke nomor handphone pemilik sepeda motor. Buzzer dapat dimatikan menggunakan RFID tag yang sesuai dan melalui SMS yang dikirimkan ke nomor pada GSM SIM800L. Teks SMS yang akan dikirim tersebut harus sesuai dengan teks yang telah diinputkan pada program. Data yang diambil yaitu berupa waktu yang dibutuhkan sistem SIM 800L untuk mengirimkan SMS dan misscall sampai ke handphone pemilik sepeda motor yakni nomor (+6285272066289). Hasil catatan waktu yang diperoleh dengan menggunakan stopwatch diperlihatkan pada Tabel 5. 
Tabel 5 Pengukuran waktu notifikasi ke handphone pemilik sepeda motor setelah sensor tertutup sebanyak empat kali

\begin{tabular}{ccccc}
\hline & $\begin{array}{c}\text { Waktu } \\
\text { delay SMS (s) }\end{array}$ & $\begin{array}{c}\text { Waktu delay } \\
\text { misscall 1 (s) }\end{array}$ & $\begin{array}{c}\text { Waktu delay misscall 2 } \\
(\mathbf{s})\end{array}$ & $\begin{array}{c}\text { Waktu delay misscall } \\
\mathbf{3}(\mathbf{s})\end{array}$ \\
\hline 4,4 & 7,3 & 64,5 & 114,1 \\
& 5,3 & 8,0 & 59,7 & 111,3 \\
& 5,9 & 9,4 & 60,8 & 114,7 \\
& 5,7 & 8,7 & 60,6 & 111,5 \\
\hline Rata-rata & 5,8 & 9,7 & 60,1 & 112,2 \\
\hline
\end{tabular}

Hasil pengukuran didapatkan bahwa waktu delay rata-rata yang dibutuhkan SIM 800L untuk mengirimkan SMS, misscall 1, misscall 2 dan misscall 3 ke handphone pemilik sepeda motor berturut-turut adalah 5,42 s, 8,62 s, 61,14 s dan 113,16 s.

\section{KESIMPULAN}

Berdasarkan pengujian dan analisis yang telah dilakukan, maka didapatkan kesimpulan bahwa rancang bangun sistem pengaman sepeda motor menggunakan RFID dan notifikasi melalui handphone telah berhasil dilakukan. RFID telah dapat digunakan sebagai pengganti kunci kontak sepeda motor dengan jarak pembacaan maksimal rata-rata dari RFID tag oleh RFID reader adalah $1,26 \mathrm{~cm}$. Sensor reed switch dapat membaca pergerakan roda depan sepeda motor dengan baik. Ketika sensor reed switch telah mendeteksi keberadaan magnet permanen melebihi tiga kali maka sensor memberi perintah untuk menghidupkan alarm dan mengaktifkan GSM SIM 800L untuk mengirimkan SMS disertai dengan misscall tiga kali ke handphone pemilik sepeda motor. Waktu delay rata-rata SMS dan miscall berturut-turut adalah 5,42 s, 8,62 s, 61,14 s dan 113,16 s. Buzzer dapat dimatikan dengan menggunakan RFID tag yang telah diinputkan ke dalam program dan melalui SMS pada handphone yang dikirimkan ke nomor dalam GSM SIM 800L.

\section{DAFTAR PUSTAKA}

Hakim, A.R., 2017, Rancang Bangun Sistem Pengaman Motor Menggunakan Radio Frequency Identification (RFID) dan Sensor Reed Switch, skripsi, Fisika, Universitas Andalas, Padang.

Rachmat, R.R. dan Julian, E.S., Pengaman Sepeda Motor Berbasis Mikrokontroler, JETri, 13(2), 2016, hal.1-10.

Veigas, M.A., Shirke, L. M., Desai, S. S. dan Naik, S. R., Safety Automation System Using Pic Microcontroller, IJSTE, 2, 2016, hal.4-8.

Badan Pusat Statistik, 2017, Statistik Kriminal 2017, https://bappenas.go.id/files/data /Politik_Hukum_Pertahanan_dan_Keamanan/Statistik\%20Kriminal\%202017, diakses Juni 2018.

Mukherjee, A., 2016, Security Access Using RFID Reader, www.Arduino.cc, diakses Maret 2018. 